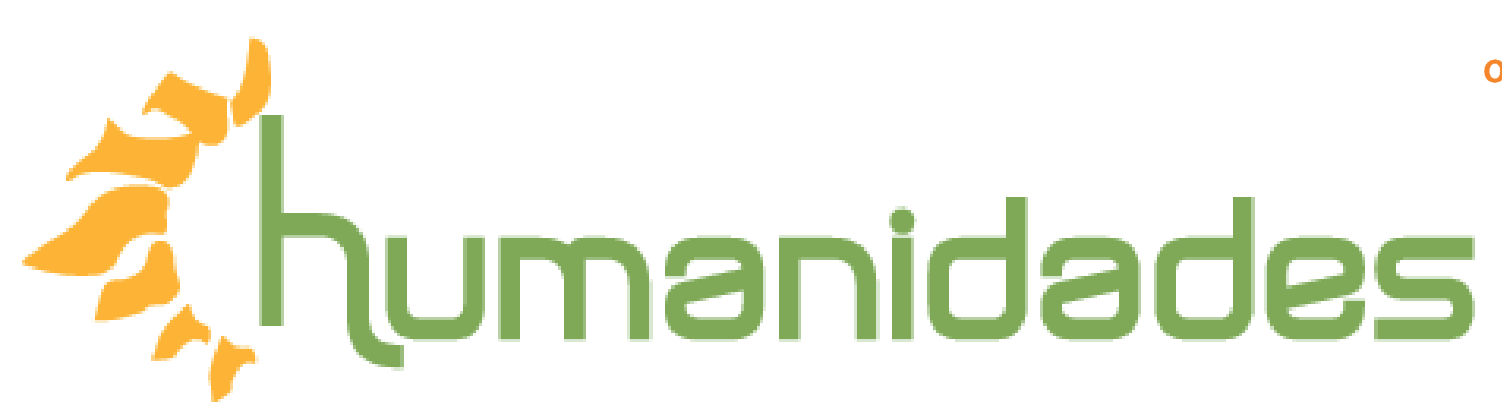

Revista de la Escuela de Estudios Generales, Universidad de Costa Rica

Julio-diciembre, 2018 •Volumen 8, número 2 • EISSN 2215-3934 •pp. 1-21

Recibido: 19-Enero-2018 Aceptado:17-Abril-2018

\title{
La disputa del ser: voces y saberes en las mujeres, las pugnas coloniales, el Estado y el progreso en Calypso, de Tatiana Lobo
}

DOI: http://dx.doi.org/10.15517/h.v8i2.33338

\section{Máster Esteban Barboza Núñez}

Docente e investigador en la Universidad Nacional de Costa Rica, Costa Rica.

Correo electrónico:ebarbozanu@gmail.com

Todos los derechos reservados. Universidad de Costa Rica. Esta revista se encuentra licenciada con Creative Commons. Reconocimiento-NoComercial-SinObraDerivada 3.0 Costa Rica. Correo electrónico: humanidades@ucr.ac.cr / Sitio web: http://revistas.ucr.ac.cr/index.php/ humanidades 


\title{
La disputa del ser: voces y saberes en las mujeres, las pugnas coloniales, el Estado y el progreso en Calypso, de Tatiana Lobo
}

\section{Resumen}

El artículo explica, haciendo uso de herramientas teóricas decoloniales, postcoloniales y de feminismos decoloniales, las tensiones y disputas en la novela Calypso, de Tatiana Lobo, en torno a la integración del sur de la provincia de Limón, escenario principal de texto, al proyecto de Estado nacional costarricense. Se analiza el contrapunteo de saberes y voces tanto locales, como exteriores, es decir, de la cultura hegemónica costarricense, a lo largo de las tres generaciones narradas en la novela y durante las cuales ocurre dicha integración. Asimismo, se analizan aspectos relacionados con las unidades de producción, la religión, la educación, las mujeres del texto, las formas de convivencias y los resultados de dichas tensiones.
Palabras claves: Crítica literaria, feminismo, estudios culturales, literatura latinoamericana.

\section{The Dispute of Being: Voices and Knowledge in Women, Colonial Clashes, the State and Progress in Calypso, by Tatiana Lobo}

\begin{abstract}
The article explains, using decolonial, postcolonial and decolonial feminist theoretical tools, the tensions and disputes in the novel Calypso, by Tatiana Lobo, around the integration of the south of the Limón province, main setting of the text, to the Costa Rican national State project. The article analyzes the contrapuntal interaction of knowledge and voices, both local and external, that is, from the hegemonic Costa Rican culture, through the three generations narrated in the novel and through which the integration occurs. Also, the text analyzes aspects such as the units of production, religion, education, women, ways of life and the results of such tensions.
\end{abstract}

Keywords: malecu people, ogres (muérra maráma), choice, agent's responsibility, third party responsibility 
El epígrafe con las dos definiciones de la palabra calypso al inicio del texto lo advierte bien desde el principio. El título de la novela de Tatiana Lobo (1996) es tan sugerente y da para tanta especulación como las dos grandes posibilidades de significación que este admite: por un lado, el ritmo afrocaribeño que narra una historia, con origen informativo clandestino entre esclavos africanos y que en principio comunicaba las noticias cotidianas y las maldades de los amos coloniales. Por otro, el origen griego, el nombre de una deidad, reina de la isla de Ogigia, recurrente en epopeyas como La Odisea, de Homero, y que retuvo a su personaje principal en su lecho por varios años hasta que fue obligada por Zeus a dejarlo marchar, ante la insistencia del héroe griego de querer regresar con su esposa Penélope. Calypso es una novela en la que ambas derivaciones se entrelazan, en relaciones no del todo armoniosas, y en las que los modos de vida, los saberes, las miradas y las concepciones básicas acerca del bienestar, la felicidad, el tiempo, las relaciones de género, la religión y la medicina periféricas se enfrentan a sus concepciones equivalentes moderno/coloniales, y entran en conflicto con estas, lo que genera la tensión necesaria para que la novela discurra y sirva de escenario para narrar la integración del sur de la provincia de Limón al proyecto nacional costarricense a lo largo de siglo XX.

La tensión generada en la novela proviene de una constante lucha. Por un lado, están las mujeres negras que aparecen en ella, Amanda, Eudora, Matila y Miss Emily; el mundo ancestral al cual están conectadas consciente o inconscientemente; los hombres importantes de sus vidas y de la vida de su comunidad anterior a la concreción de la conexión con el resto de Costa Rica como nación. Por otro lado, el proyecto expansivo nacionalista capitalista que se extiende desde el Valle Central, en el interior del país, de la mano del personaje Lorenzo Parima. Este proyecto termina por imponer una idea occidentalizada y patriarcal de nación, de las relaciones interpersonales y de la producción de riqueza que oblitera, con el paso de las generaciones, los saberes ancestrales que se resisten a desaparecer y que persisten fuera del eurocentrismo y de siglos de explotación y esclavitud mercantilista y capitalista.

Esta tensión también se establece en la colisión entre un mundo ancestral, femenino, orgánico, con saberes y nociones de mundo básicas singulares y diferenciadas de cánones occidentales, y el progreso moderno. El concepto de tiempo de ese mundo es otro -con recurrencia a los ancestros para organizar el presente y el

\section{Introducción}


futuro-; lo mismo sucede con la medicina - con hierbas y saberes desconocidos o censurados por la práctica occidental como medios de curación-; la organización comunal distinta a la nacional, gracias, en un inicio, a una institucionalidad estatal y religiosa débil que permite modos alternativos de asociación.

Ahora bien, tenemos la intromisión de un mundo moderno y patriarcal en el poblado que sirve de escenario principal en la novela y en el que la acumulación capitalista, la religiosidad occidental, la noción moderna de progreso y las unidades de producción de riqueza como el turismo entran en conflicto y terminan derrumbando esas otras realidades anteriores. Los personajes femeninos de la novela, principalmente Amanda, Eudora, Matilda y Miss Emily, y sus relaciones con el mundo que las rodea y con personajes masculinos subalternos afines a ellas, como Plantintáh Robinson, el predicador Africano o el hierbatero, funcionan como territorios en disputa y como bastiones de las alteridades que, con el paso de las generaciones, ceden terreno a una colonialidad del ser que las borra y las subyuga.

Con estas nociones preliminares, el objetivo principal de este trabajo es explicar, haciendo uso de herramientas teóricas decoloniales, postcoloniales y de feminismos decoloniales, cómo se dan estas disputas y cómo la novela se yergue como un campo de batalla intergeneracional entre un mundo precapitalista, comunitario, más solidario y menos patriarcal, y el nacionalismo étnico metafísico, capitalista y patriarcal encarnado en Lorenzo Parima, principal antagonista de estas alteridades.

El análisis del accionar de los personajes subalternos, específicamente Miss Emily y las tres mujeres mencionadas anteriormente, y que otorgan título a las tres secciones de la novela, y la disputa de saberes y formas de organización se pueden analizar utilizando tres vertientes teóricas que pueden ser entrelazadas entre sí, con el fin de dar una mayor dimensión al análisis de la novela. Por un lado, tenemos el concepto de la colonialidad, de Aníbal Quijano (1992), aunado a algunas de las propuestas feministas decoloniales formuladas a partir de los primeros años del siglo XXI y aún en construcción, planteadas principalmente desde América Latina, aunque también desde otras latitudes (Bidaseca, 2010; Mohanty, 2011; Hernández, 2011). Por otro lado, tenemos el análisis crítico de la formación de la identidad nacional costarricense, según propuestas desde la filosofía (Jiménez, 2002), la historia (Molina, 2003) y la literatura (Singer, 2006; Ovares et al, 1993; 
Quesada, 1986), cluyo arsenal discursivo, hegemónico y totalizador, que sigue la línea de discursos coloniales y patriarcales, analizado y cuestionado por estos autores, y que puede también ser cuestionado por la crítica decolonial, postcolonial y el feminismo decolonial, discurre a lo largo de la novela y antagoniza con los valores propuestos por los personajes subalternos

\section{Estado y nación costarricense, patriarcado y colo- nialidad: Algunas nociones preliminares}

El Caribe costarricense ha sido, a lo largo del siglo XX e inicios del XXI, un territorio fértil para el florecimiento de obras literarias que hacen de ese espacio su universo, desde la generación del 40, con obras canónicas de la literatura costarricense como Mamita Yunai (1941), de Carlos Luis Fallas, hasta conspicuos casos contemporáneos como Limón Blues (2002), Limón Reggae (2007), de Anacristina Rossi, y la misma Calypso, de Tatiana Lobo. La costa caribeña, aún en los siglos XIX y XX, fungió como zona de contacto, para usar la terminología de Mary Louise Pratt (2010), en la que confluyeron intereses transnacionales como los de la United Fruit Company (UFCO), entrelazados con los de la oligarquía nacional de finales del decimonónico, de extender hasta Limón su proyecto de formación de una identidad nacional a partir de ideales liberales adoptados por dicha cúpula en la segunda mitad del siglo XIX.

Asimismo, en dicha costa confluyeron la migración jamaiquina, llegada para la construcción del ferrocarril desde San José, en el centro del país, y que luego se quedaría como mano de obra en la gran plantación bananera; la migración del Valle Central y de otras regiones del país, atraída por las oportunidades de empleo que ofrecía la UFCO; y otros grupos migrantes de otras nacionalidades. Entonces, culturalmente hablando, la provincia caribeña de Limón se yergue como zona de contacto y de conflicto entre distintos intereses, capitales, etnias, religiones, nociones de mundo y saberes que en ocasiones de modo tenso y conflictivo forjarían la historia de la región, rica, dinámica y dramática.

El primer componente de dicha historia es el del proyecto de forja de una identidad nacional en la joven república, que a mediados del siglo XIX aún experimentaba tensiones a la hora de definirse, ya sea como un proyecto nacional independiente, o bien ceder a los intereses unionistas centroamericanos que también tenían sus 
partidarios, tanto en la recién independizada provincia, como en las otras provincias de la antigua Capitanía General de Guatemala. La filosofía liberal, adoptada por las clases dominantes de San José, ayudó a volcar la balanza hacia el proyecto nacional independiente. Ya para la década de 1870 esa ideología se tornaba hegemónica y uno de sus principales objetivos era el de la europeización de Costa Rica, a través del blanqueamiento ideológico de su población. Esto tenía como fin legitimar a las clases dominantes, mayoritariamente descendientes de criollos, tornar al país atractivo para la llegada de migrantes europeos por medio de contratos de colonización, e impulsar el libre comercio y la inversión extranjera directa, como la que propondría Minor Keith en Limón a cambio de la conclusión del ferrocarril al Caribe por parte de su compañía.

Como apunta Iván Molina (2003), ya para finales del siglo XIX la historiografía costarricense situaba el pasado de la nación en las expediciones de Colón en 1502, con tal de acentuar el origen europeo de esta. Al mismo tiempo, se centraba la visión de los pueblos indígenas en asuntos arqueológicos o museográficos, mientras se despreciaban sistemáticamente poblaciones mayoritariamente mulatas o mestizas, como las de Guanacaste, y trabajadores chinos o jamaiquinos que para esa época llegaban en números considerables a trabajar en la conclusión del ferrocarril a Limón.

Estas visiones de nación, que terminarían imponiéndose y definiendo lo que incluso hasta el día de hoy muchos creen que en parte definen a Costa Rica, generaría lo que Alexander Jiménez (2003) ha llamado un nacionalismo étnico metafísico. Es decir, una idea de una Costa Rica imaginada como blanca, con raíces en la racionalidad, el progreso y en valores totalmente rastreables a Europa, y que nada tienen que ver con la hibridez o la alteridad, ni étnica ni ideológica. Esto ayudó a diferenciar a Costa Rica, como una nación supuestamente blanca, con valores europeos, de otros proyectos nacionales, especialmente en Centroamérica. Entonces, características como el individualismo, el pacifismo, el trabajo y la laboriosidad, la idea occidental de lo civilizado, lo culto y el progreso capitalista, atribuidos al mundo europeo, fueron colocados en contraposición con lo irracional, lo conflictivo, lo salvaje, lo atrasado y lo inculto con que se trataba de caracterizar desde Costa Rica a otros proyectos nacionales en otros países centroamericanos.

Como apunta Deborah Singer (2006), esta visión europeizante que prácticamente 


\section{La disputa del ser: voces y saberes en las mujeres....}

mantuvo intactos los valores y la posición de privilegio de las clases dominantes anteriores a la independencia, también tendría sus efectos en asuntos de género. En su análisis de la influencia de la construcción de la identidad nacional en la narrativa decimonónica costarricense, Singer afirma que el funcionamiento del orden social estuvo ligado al acatamiento de ciertas normas de índole patriarcal. Por ejemplo, la mujer es quien resguardaba del honor familiar por medio del control de sus apetitos sexuales y su respeto a la autoridad del padre y del esposo. Como estipulan Ovares et al. (1993), en la formación de la identidad nacional costarricense la nación se homologa, desde el punto de vista jerárquico, con la familia, y esto implica que deberían existir ciertos tipos de relaciones entre los miembros de la nación, como en una familia: armonía, ausencia de conflictos, origen común y respeto a la autoridad y al orden. Dentro de la familia, entonces, la autoridad del padre se legitima como el representante de la autoridad del Estado.

La mujer ideal del proyecto identitario nacional es recatada y decorosa, mientras que las extranjeras o las mujeres periféricas son desenfrenadas sexuales. Además, se veía como positivo el sometimiento de los hijos a la autoridad del padre y los sirvientes a la de sus patronos. Es decir, en ambos casos, tanto a nivel identitario como a nivel de relaciones de género, se ve la huella de los valores eurocéntricos y judeocristianos, por un lado; y capitalistas, por otro, trabajando en conjunto para forjar una idea de nación y de relaciones interpersonales que continúan sometidos a la colonialidad del poder y a las nociones patriarcales occidentales.

Para entender el concepto de colonialidad, es importante primero recurrir a la idea de Aníbal Quijano (1992), para quien “con la conquista de las sociedades y las culturas que habitaban lo que hoy es nombrado como América Latina, comenzó la formación de un orden mundial que culmina, 500 años después, en un poder global que articula todo el planeta" (p. 12). Para Quijano, los procesos independentistas latinoamericanos en realidad no terminaron con el colonialismo, más bien supusieron la llegada de una élite que desplazaría a otra, pero que seguiría la misma lógica de dominación sobre grupos subalternos.

Entonces, la colonialidad como concepto se refiere a la lógica común del colonialismo occidental, la cual ha seguido determinando las relaciones políticas, económicas, laborales, culturales y de género, aún durante el periodo independiente de las naciones del continente. Esto ha sido posible, en parte, gracias a la relación 
políticas, económicas, laborales, culturales y de género, aún durante el periodo independiente de las naciones del continente. Esto ha sido posible, en parte, gracias a la relación simbiótica entre el colonialismo expansionista europeo y la modernidad, en el binomio que tanto Quijano como Walter Mignolo (2007) han venido a denominar modernidad/colonialidad, y que, según ambos críticos, se ha nutrido simbióticamente y ha tejido las relaciones y las nociones de realidad entre centros colonialistas y sus periferias, a través de los últimos cinco siglos.

Esta colonialidad tiene una derivación denominada colonialidad del poder, según Quijano, citado por Eduardo Restrepo y Alex Rojas (2010), que funciona como el marco dentro del cual operan las otras relaciones sociales, a la vez que produce una serie de discriminaciones que maniobran como construcciones intersubjetivas, posteriormente codificadas como raciales, étnicas, antropológicas o nacionales, como si fuesen fenómenos naturales y no de la historia del poder. Esto a su vez produce otra colonialidad, la del ser, que deshumaniza e inferioriza a una determinada población, mientras se dejan otras como la expresión misma de la humanidad (Restrepo y Rojas, 2010).

Dentro de esta supuesta expresión de lo que es humano se incluyen manifestaciones artísticas, relaciones de género, concepciones de conocimiento y ciencia, conceptos de bienestar, religión y espiritualidad, formas de organización y gobierno, conceptos de nación o región, entre muchas otras características de la convivencia humana que, a pesar de haber mostrado gran diversidad a través de la historia en distintas regiones del mundo, al convertirse Europa occidental en un poder colonial y expansivo a escala global, quedan, o borradas completamente, o bien reducidas a manifestaciones humanas subalternas, en muchos casos hasta vilificadas por los discursos favorecidos en esta lógica moderno/colonial eurocéntrica. Es decir, como bien apunta César Germaná (2005), Europa hegemonizó el imaginario, la cultura, el conocimiento y la manera de producirlo, lo cual generó, a su vez, la exclusión de la hibridez, la multiplicidad, la ambigüedad y la contingencia (Castro-Gómez, 2000).

Evidentemente, la herencia judeocristiana europea, aunada al binomio moderno/ colonial, además de la colonialidad del poder y del ser, afectan enormemente los conceptos de relaciones de género y el lugar de las mujeres a partir de la colonización de América hasta el presente. Se va más allá del concepto general de patriarcado que supuestamente rige las relaciones entre hombres y mujeres y coloca a las segundas en posiciones de sometimiento en relación con los primeros. 
Se cita recurrentemente la ciencia moderna, la herencia judeocristiana y al saber filosófico occidental como los principales mecanismos patriarcales de opresión contra las mujeres.

Sin embargo, en un contexto de crítica decolonial y postcolonial es importante aclarar que esta posición corre el riesgo de asumir que las mujeres son una categoría monolítica y que el colonialismo poco o nada tiene que ver con la opresión de estas. Los feminismos postcoloniales y decoloniales articulan una crítica a perspectivas esencialistas y universalistas del patriarcado y de las mujeres, hasta afirmar, como en el caso de Chandra Mohanty (2011), Sylvia Wynter (1990) e Irene Lara (2007), que su esencialismo puede llegar a convertir estas perspectivas en discursos con efectos de poder que incluso colonizan las vidas de las mujeres. Esto se da al asumir a las mujeres como una categoría homogénea, independiente de raza, clase o etnia, y cuyo único factor en común es la opresión patriarcal masculina. Generalmente, según Rosalva Hernández (2011), esto va a producir una mujer del así llamado "Tercer Mundo" como circunscrita al espacio doméstico, víctima, ignorante, pobre, atada a la tradición y opuesta a la académica feminista, quien es liberada, educada, moderna y en control de su propio cuerpo y sexualidad.

Estos esencialismos también corren el riesgo de invisibilizar las luchas de otras mujeres que, desde discursos y prácticas situadas fuera de la matriz colonial de poder, también tratan de articular sus identidades, sus formas de vida, sus nociones de relaciones de género y de conocimiento, y que a menudo se viven como múltiples y contradictorias en relación con los discursos dominantes que las tratan de someter. Es por eso que críticas como la misma Hernández (2011) llaman a historizar y contextualizar las formas que asumen las relaciones de género para evitar el universalismo feminista; a considerar la cultura como un proceso histórico para evitar esencialismos culturales, y a reconocer que las luchas sociales de las mujeres están insertas en procesos globales de dominación capitalista.

Así las cosas, y una vez esbozados algunos conceptos básicos acerca de la colonialidad y los feminismos decoloniales, no cabe duda que procesos como el de la formación del concepto de nación costarricense también pueden ser sometidos a análisis según las perspectivas decoloniales, postcoloniales y de los feminismos decoloniales, como una manifestación más reciente del discurso colonial que no 
solamente narra y sistematiza las relaciones entre los poderes coloniales modernos y sus periferias, sino que además sirve de enunciador y codificador de conocimiento, sujetos, género, cultura, economía y muchas otras manifestaciones humanas. Todos aquellos sujetos que no lograron insertarse en el imaginario liberal europeizante de finales del siglo XIX, como por ejemplo las poblaciones afrodescendientes que aparecen en Calypso y sus modos de vida van a sufrir una nueva colonización postcolonial, discursiva, laboral, territorial y de género, y que precisamente se esbozan en la novela de Lobo.

Esta nueva colonización incluye también el proyecto de construcción de identidad nacional, impuesto desde arriba hacia abajo por las clases hegemónicas y desde el centro del país hacia periferias como Guanacaste o Limón. A juzgar por las características de este proceso, esbozadas anteriormente y contrastadas con la teoría decolonial, es posible observar que el binomio modernidad/colonialidad sin duda alguna juega un papel importante en su formulación y en su implementación. Esto demuestra que Costa Rica, al igual que otros proyectos latinoamericanos de construcción de imaginarios nacionales, no escapó de la tendencia decimonónica de imaginar naciones lo más cercanas posibles a las antiguas metrópolis coloniales.

\section{Colonialidad, decolonialidad y resistencia: La disputa de los saberes y poderes hegemónicos y sus contrapar- tes periféricas en Parima Bay}

Calypso como narrativa expone las disputas entre los saberes hegemónicos occidentales y lo subalterno, ya sea en aspectos de género, económicos, de conocimiento y de religión, que, a lo largo de la obra, presentada en forma de argumento lineal, colisionan en ocasiones de manera frontal, en ocasiones sutilmente, con la subalteridad, a la vez que esta, en ocasiones muestra subversión y resistencia.

Desde el inicio de la novela, los dos personajes fundacionales de la narrativa, Plantintáh Robinson y Lorenzo Parima se yerguen como polos opuestos de figuras masculinas. Plantintáh es guapo y fornido, Lorenzo es poco atractivo y físicamente débil. Plantintáh tiene un castellano "de vocales acostadas, arrastrando erres, confundiendo pronombres, y convirtiendo artículos en algo tan indefinido que nunca se sabía el género exacto de sus sustantivos" (Lobo, 1996 p. 14). Mientras 
que Lorenzo es un "blanco incapaz de resistir las mudanzas y los caprichos del mar" (p. 18), en referencia a los mareos que le produce el viaje desde el puerto de Limón hasta el sur de la provincia, donde ambos se proponen abrir un comisariato. Una vez el local comercial entra en funcionamiento, Plantintáh descuida sus obligaciones laborales para pasar tiempo con Amanda, su esposa. Ambos parecen “dos avecillas extasiadas en su mutua contemplación” (p. 29), al tiempo que Lorenzo no descuida detalle al apuntar todo lo que el primero debe en el abastecedor, con un claro objetivo de beneficiarse y al mismo tiempo hundir a Plantintáh, por la gran cantidad de enseres y utensilios que este adquiere para su hogar y el de Amanda.

La confusión del género en el idioma castellano del primero o la poca importancia que le da a la acumulación capitalista no son características gratuitas. Revelan no solo una otredad lingüística y racial, sino también una subversión al orden lógico civilizatorio moderno, por un lado, en el descuido del lenguaje de la cultura dominante nacional, en este caso el español, como símbolo de civilización; y, por otro lado, en la poca importancia que le da al sistema que ordena la mayoría de las relaciones humanas, el capitalismo. Lorenzo, por su parte, se siente fuera de lugar en el agua, en lo fluido, en lo cambiante, y prefiere ampararse en la firmeza y la estabilidad de la tierra y en la acumulación de riqueza, aunque esto conlleve afectar negativamente a su socio. Así se las arregla para instaurar el germen del capitalismo en la zona, además de la usura, el gamonalismo, y la consecución de sus objetivos, aunque tenga que asesinar para lograrlos.

El duelo de valores, saberes, poderes y visiones de mundo entre ambos personajes se mantiene a lo largo de la novela, a pesar de que Lorenzo asesina a Plantintáh, a quien ve como obstáculo para apropiarse de Amanda, casi desde inicio de la obra. A pesar de que la destrucción de Plantintáh parece segura con su asesinato, su recurrencia desde el más allá y sus duelos con Lorenzo, no obstante, la racionalidad del primero y su desprecio a las costumbres y las creencias afrocaribeñas, demuestran que la colonialidad, que trata de aplacar otras realidades, no necesariamente triunfa en la novela. El ver los huesos de Plantintáh una vez que ordena la exhumación de su cadáver, a raíz de una obsesión suya de cerciorarse de que realmente está muerto, no es suficiente para convencerse de que realmente este no está presente, como una aparición 
Así, "ni la terrible visión [de ver los huesos] lo convenció de que el muerto estaba definitivamente muerto; un fuerte olor a bayrum se desprendió cuando volvieron a echarle paladas de tierra encima" (p. 54). Ni la racionalidad, ni la codicia capitalista, ni el afán civilizatorio de Lorenzo logran aplacar al fantasma de Plantintáh, que le acosa y perturba sus ambiciones, especialmente cuando Lorenzo demuestra sus intenciones de poseer a Eudora, la hija de Plantintáh y Amanda. Parima admite la presencia del fantasma como una fuerza operante e influyente, y muchos de sus planes se ven frustrados por las apariciones de Plantintáh. La idea de progreso positivista y lineal de Parima es perturbada a lo largo de texto por los saberes ancestrales y la noción del tiempo, en el cual el futuro está en el pasado, a través de la continua presencia de su antiguo socio.

Los polos opuestos que representan estos dos personajes se ven reflejados y son replicados en otros saberes fundamentales, costumbres y en otros actores que se enfrentan en el plano material e ideológico. Por ejemplo, Miss Emily, hermana de Plantintáh, y el Africano, un predicador que llega para establecer una Iglesia cristiana basada en la ayuda mutua, el aliento y en el confortamiento espiritual, establecen un concepto de religión y espiritualidad basado en la funcionalidad de esta y en aspectos que puedan beneficiar directamente a la comunidad, más allá del control y la sumisión del cristianismo colonial. Miss Emily lo hace con de su capacidad de conectarse con el mundo de los ancestros y servir de canal para que estos influyan, aún después de muertos, en el devenir diario de la comunidad. El Africano porque desconecta la religión cristiana de aspectos e intereses colonialistas, civilizatorios y monetarios, con una clara visión anticapitalista, a través de la cual insta a los lugareños a "no sudar más de lo necesario" (p. 62) por el pan de cada día, lo cual evidentemente es una afrenta a los intereses de Lorenzo y su proyecto civilizatorio. El predicador demuestra su capacidad de darle un uso subversivo a la religión impuesta por sus antiguos amos europeos.

Evidentemente este intento del Africano de decolonizar el cristianismo no carecerá de contestación por parte de Lorenzo, quien al ver amenazado su lugar, especialmente ante los reproches que le lanza el Africano por haber asesinado a Plantintáh, recurre a la religión católica, institucionalizada y civilizatoria, para frenar la subversión y destituir al predicador negro. No gratuitamente, tanto el obispo a quien Parima le pide ayuda, como el sacerdote que llega a impartir la doctrina católica, son europeos. A los pariminos, como se hacen llamar 


\section{La disputa del ser: voces y saberes en las mujeres....}

los pobladores de la aldea fundada por Lorenzo y Plantintáh, el Africano "les había entregado su tiempo y sus buenos concejos a cambio de ropa vieja" (p. 74) y al adoptar la doctrina del advenedizo cura católico estos le traicionan, como bien apunta el jamaiquino, segundo esposo de Amanda.

Apenas llega al pueblo, el sacerdote alemán deja claro "su oposición a los ritos paganos y a las costumbres ajenas al culto del dolor y de la austeridad" (p. 75), al tiempo que Lorenzo lo utiliza para desplazar al incómodo Africano; una vez que lo logra, pierde interés en la evangelización del lugar por parte del sacerdote europeo. En este caso vemos a una religiosidad, la católica, desconectada de la espiritualidad y de la tierra, como nada más que un instrumento que colabora con los intereses de Parima. Sin embargo, cuando tanto el predicador como el misionero desaparecen del pueblo, "Parima Bay cayó en el paganismo total y los ritos de la pocomía florecieron entre el follaje nocturno, pero como no alteraban los negocios del comisariato, Lorenzo se despreocupó” (p. 79).

La resistencia y los otros saberes persisten, y Miss Emily es uno de esos bastiones de resistencia. Conectada al mundo natural y al mundo ancestral, se sigue resistiendo a la colonialidad del ser, impuesta por los valores nacionales modernos. Otros bastiones de resistencia son, por ejemplo, el hierbatero, quien cura usando hierbas y saberes que están fuera de la civilización occidental, sin pedir nada a cambio, y que se contrapone a Lorenzo, que cobra por adelantado el transporte de cualquier enfermo a la ciudad de Limón para que reciba atención médica moderna.

Además de las ideas de bienestar y religión, las de educación, ciencia e incluso literatura, tanto sus versiones coloniales como sus contrapartes de resistencia, se enfrentan en Parima Bay. El primer maestro de la aldea es un jamaiquino, devoto de la reina Victoria, quien internaliza el discurso colonial británico. La instauración del recinto educativo sustituye a la iglesia como mecanismo de control: "frente a la bulliciosa escuela se marchitaba la ermita. La selva se le metía por las rendijas, las culebras anidaban donde había estado el altar... lo mismo que en la casa del Africano" (p. 91).

El jamaiquino introduce a las letras a los niños del lugar "con sangre" y su estricta enseñanza hace que se aplaquen "las insubordinaciones y los alumnos aprendieron a leer y a escribir" (p. 92). A pesar de que entra en conflicto con Lorenzo, quieen 
quiere impulsar el modelo educativo del Valle Central y obliga al maestro a cambiar el nombre de la escuela, de Queen Victoria School a Escuela de Parima Bay, este dona libros de texto y cuadernos, en una clara señal de querer mantener el control y el gamonalismo aún en el incipiente sistema educativo. Más adelante en la novela, como se analizará en este trabajo, Eudora va a tratar de decolonizar y revertir el proceso de adoctrinamiento, no solamente oponiéndose al sistema educativo, sino también al poder de Lorenzo.

El entomólogo, un científico alemán que resultó ser un nazi en fuga, o Mr. Bowls, un escritor estadounidense que se establece en Parima Bay para terminar una novela ubicada en el metro de Nueva York, son otros dos representantes del conocimiento y las letras occidentales que al final sucumben. El primero ante la selva que rodea Parima Bay y el segundo ante Priscilla Taylor, con quien engendra a Stella, otro importante personaje de la novela. Ambos abandonan sus saberes y hábitos, de científico y escritor, lo que demuestra que el contrapunteo subversivo decolonial del lugar y sus habitantes se resiste a desaparecer, y que no solamente se da una colonización y una imposición de un saber sobre otro, también hay resistencias y brechas que hacen resurgir el espacio y los saberes ancestrales a pesar del paso del tiempo.

Poco a poco, sin embargo, el progreso civilizatorio patriarcal capitalista y positivista se impone, primero con la apertura del camino a Limón, luego con la llegada de la electricidad, que acrecienta el consumismo y la desconexión con la naturaleza por parte de los habitantes locales. También se da con la sustitución de hábitos locales, como la pasión por el cricket, principal deporte de la tierra ancestral, Jamaica, por la del fútbol, deporte predilecto del Valle Central de Lorenzo; o bien la llegada del turismo extranjero que definitivamente marca el fin de una era.

\section{Las otras mujeres, su resistencia y subversión de- colonial}

Como contrapunto de resistencia contra la colonialidad del poder y del ser, los personajes femeninos de la obra también juegan un papel importante en Calypso. En la noción patriarcal de Lorenzo, estas funcionan como territorios en disputa. No en vano las tres mujeres Scarlet, Amanda, Eudora y Matilda le dan título a las 
tres secciones de la novela que relatan los acontecimientos que transforman la región a lo largo de tres generaciones.

El primero de estos personajes, Amanda, es vista por Lorenzo como un objeto de deseo y obsesión sexual. Su belleza física le rompe los esquemas estéticos europeizantes al advenedizo del Valle Central y lo hace pasar de percibir el ideal de belleza femenino de "la estampa de un almanaque con la propaganda de Mejoral, donde se veía a una rubia de sonrisa pícara, cutis de porcelana y grandes pechos rosados encaramada en un asiento de un bar" (p. 16), a la figura de Amanda, "obra perfecta de la naturaleza, [en la que] todas las artes de África se habían puesto de acuerdo en definitivo consenso" (p. 24). Sin embargo, esa belleza no transforma a la joven prometida de Plantintáh en repositorio de genuinos sentimientos afectivos por parte de Lorenzo, sino que este la ve dentro de la otredad, la doble otredad que le asigna su condición de mujer y de negra. Al verla bailar con Plantintáh, Lorenzo piensa que "si fuera él... la estrujaría en sus brazos y la obligaría a declararse sierva, convicta y rea" (p. 25). De ahí su obsesión y el derecho que reclama para sí mismo de poseerla, y a su hija y a su nieta, a toda costa, en una visión de Amanda que no la aleja de la otredad esclavizadora que no necesariamente tiene la rubia de la estampa de Mejoral.

Como demuestran las críticas feministas postcoloniales y decoloniales citadas anteriormente, las mujeres étnicamente diversas en relación al patrón hegemónico occidental presentan otras luchas, además de las que supone la resistencia al control meramente patriarcal. En el caso de Amanda, esta también tiene que lidiar con sus desventajas económicas a las que le circunscribe el poder de Lorenzo, no solo patriarcal, sino de clase y de etnia, primero al asesinar este a su marido, Plantintáh, y luego al chantajearla con hambre para que esta acceda a ser su sierva, su convicta y su rea.

Al negarse a ser su esposa, a pesar de todas las ventajas económicas que ello podría suponer, Amanda se resiste al sometimiento; y al decidir vivir con el jamaiquino, en vez de hacerlo con Lorenzo y sumirse en la vida austera pero sin complicaciones ni ambiciones materialistas, no solo desconcierta a Parima, quien no puede explicarse, según sus principios, una decisión tal, sino que demuestra que existen otros modos de vida y otras maneras de establecer relaciones interpersonales que pueden ser más deparadoras que el dinero, el estatus social y el poder. 
Miss Daisy, quien se casa con Lorenzo hasta que muere de un infarto, vivió en el comisariato rodeada de bienes materiales, pero menos plena y más infeliz que cualquier parimino pobre.

La segunda Scarlet, Eudora, presenta una transición entre ese mundo del sur de la provincia de antes de Lorenzo a las transformaciones que vendrían después. A pesar de los esfuerzos de su tía Miss Emily, Eudora no puede conectarse con el universo de los ancestros. Es más racional, influenciada por el maestro victoriano, y sus últimas posibilidades de conectarse con ese mundo alterno parecen perderse cuando en una de sus últimas travesuras de niña, cuando fisgonea en la habitación del entomólogo alemán que hospedaba su tía, a la espera de ver las mariposas que el supuesto científico coleccionaba, en su lugar topa con aterradores murciélagos y el mundo fantástico que tenía en su cabeza, de mariposas que volaban hasta encontrarse con la luna, desaparece para siempre.

Sin embargo, también presenta aspectos importantes de resistencia. Una vez que se convierte en la maestra del pueblo, hace que los niños coloreen de marrón oscuro los dibujos de niños blancos que aparecen en los libros de texto, hasta que llega "un inspector de escuelas y reclamó por lo que consideró un desacato y una falta de respeto a la enseñanza oficial del Estado" (p. 149). Acá vemos una subversión no solamente a la enseñanza oficial, como menciona el inspector, sino también a la estética eurocéntrica y a la colonialidad del ser, que pone como representantes de toda la niñez a los niños blancos retratados, quienes para nada reflejan a los escolares de Parima Bay, que no salen representados en el discurso oficial del Estado eurocéntrico costarricense.

No obstante, el aspecto más importante de resistencia de Eudora a los constructos hegemónicos es de índole sexual, específicamente, cómo controla su propia sexualidad y su propio cuerpo, más allá de las normas impuestas por la sociedad patriarcal que coloniza su aldea. Si bien es cierto Lorenzo consigue desterrar a su pretendiente local y más tarde la convence de casarse con él, nunca puede cumplir su fantasía de hacerla suya sexualmente. Al contrario, y transgrediendo todos los preceptos patriarcales que rigen los estándares que Parima representa, Eudora encarna al opuesto de la mujer recatada, pulcra, decorosa y sometida, de la que nos hablaba anteriormente Deborah Singer, según el ideal imaginado nacional. Este personaje asume el control de su sexualidad, que transgrede la monogamia 


\section{La disputa del ser: voces y saberes en las mujeres....}

matrimonial, e incluso la heteronormatividad, al frecuentar amantes de ambos sexos. A través de estas aventuras, la segunda Scarlet demuestra otras posibilidades de establecer relaciones interpersonales y de vivir la sexualidad, más allá de las formas que dictan la religiosidad y la institucionalidad occidentales, sin necesariamente quedarse estancada en ese estadio, como demuestra más adelante en la novela, al establecer una relación seria con el maestro que ha venido a sustituirla, por orden de Parima, hasta que tiempo después este decide abandonarla para regresar al centro del país.

La última Scarlet, Matilda, con quien termina la saga, a pesar de que logra ver el espectro de Plantintáh cuando este regresa de su periplo por África, no lo logra identificar, ni le interesa realmente saber quién es o estar conectada con sus ancestros. La rebeldía contra su supuesto padre, Lorenzo, porque sabemos que en realidad fue engendrada por un turista, miembro de una comuna hippy que luego se marchó; las fantasías de juegos piratas que en su infancia practica con sus amigos; y la empresa de asaltar contenedores son los únicos resabios que le quedan aún por colonizar. Sin embargo, su trágico fin, asesinada por encargo de Lorenzo, sin que este sepa a quién realmente está mandando a matar, es un síntoma de la decadencia que se ha apoderado de Parima Bay y de cómo la última faceta de sus transformaciones, el narcotráfico, como un cataclismo parecido al que cierra la narrativa, ha terminado por imponerse a la alteridad anterior a la llegada de Lorenzo al lugar.

Este suceso coincide con la partida definitiva de Miss Emily al más allá. Ella es quien, a fin de cuentas, mejor encarna esos saberes alternos en toda la obra, fuera de la civilización occidental. Es el canal que conecta a ambos mundos, a través del cual Plantintáh se comunica y con él los demás ancestros. Ella es quien le transmite, aún en estado catatónico, en el que queda inmersa por años, su sabiduría a Stella, la única que puede escucharla, pero que pierde sus facultades al revelar las danzas sagradas a los turistas por dinero. Con su certeza de que:

El mundo cambia y puede hacerse diferente a voluntad, que basta el abandono de sí mismo para poder ver un dopi y las cosas más transparentes, que si uno sabe penetrar en el mundo de los seres que no tienen explicación, cambian las formas y los colores, lo denso se hace delgado y lo pesado, liviano (p. 106). 
Ella es quien mejor entiende que el proyecto civilizatorio de Lorenzo. La acumulación capitalista de este personaje, su religión, su Estado y su patriarcado no son más que construcciones impuestas que no están escritas en piedra, como la mayoría cree, y tampoco representan el total de lo que califica como humano, por lo que la resistencia de Miss Emily reivindica no solo su propia lucha, sino la de las otras mujeres y hombres de la obra, que con sus alteridades resisten la colonialidad del ser y del poder que se les impone. Su resistencia es feminista, pero también decolonial, y su lucha no es solamente contra el patriarcado, sino contra toda la institucionalidad moderno/colonial que atenaza el sur de Limón.

\section{Conclusiones}

Calypso es el campo de batalla de los saberes, las formas de vida y las visiones de mundo tanto de los afrodescendientes como de Lorenzo Parima y su visión del progreso, la moral y los cambios que estos representan. Las confrontaciones que suceden en el lugar demuestran que ni un bando ni otro son instancias monolíticas, ni una oblitera completamente a la otra, sino que es posible establecer un contrapunteo decolonial en el que, de múltiples maneras, los saberes y las formas de vida subalternas muestran resiliencia y aparecen y reaparecen en el texto, en formas no del todo aceptadas por la razón moderno/colonial, pero que sin embargo están ahí.

A pesar de que la novela en ocasiones parece idealizar a la cultura afrocaribeña, como bien lo ha señalado Jorge Chen Sham (2008), o bien tiende a invisibilizar a los grupos indígenas, participantes importantes en la historia del sur de Limón, no deja de mostrar matices que demuestran, por un lado, la influencia de las ideas liberales en la propagación del ideario nacional costarricense en todo el territorio nacional. Por otro lado, enfatiza los efectos de estas ideas en grupos étnicamente subalternos; en las mujeres, relegadas, en el caso de las habitantes de Parima Bay, a una doble otredad; y en las mutaciones de ese proyecto nacional y muchas de las derivaciones, directas o indirectas, y que culminan en la historia del Limón contemporáneo, como el turismo o el narcotráfico, a pesar de que la resistencia existe, y perdura a lo largo de casi toda la novela, y no en forma de estallidos violentos o revoluciones; más bien, como apunta Emiliano Coello (2010), en el esfuerzo de los sujetos subalternos de la novela por mantener las costumbres y tradiciones africanas. 
La aplicación de herramientas decoloniales, postcoloniales y de feminismo decolonial no solamente ayuda a entender, analizar y explicar mejor una obra literaria como Calypso; al hacer referencia a los fenómenos sociales que en ella aparecen, nos pueden servir también para la reflexión, desde otra perspectiva, acerca de los efectos del binomio modernidad/colonialidad en la creación y definición de proyectos nacionales, los intereses que se yerguen detrás de estos y sus efectos hasta hoy. La doble conciencia, esa que W. E. B. Du Bois planteaba en Las almas de pueblo negro, el problema de la "peculiar sensación de siempre mirarse uno mismo a través de los ojos de otros, de medir el alma propia con una medida de un mundo que te mira con divertido desprecio y pena" (1992, p. 199) es la que en gran medida provoca la interiorización de formas de ver el mundo y de desenvolverse en este, las cuales no necesariamente corresponden a nuestras realidades. El cambio supone empezar a ver esas alteridades, a verse como, en parte, relacionados con estas, y entender que otras formas de pensamiento y acción también son viables.

\section{Referencias}

Bidaseca, K. (2010). Perturbando el texto colonial. Los estudios (pos) coloniales en América Latina. Buenos Aires: Editorial SB.

Castro-Gómez, S. (2000). Ciencias sociales, violencia epistémica y el problema de la invención del otro. En E. Lander (Comp.), La colonialidad del saber: Eurocentrismo y ciencias sociales (145-161). Buenos Aires: CLACSO.

Chen, J. (2008). Las limitaciones del exotismo: el bondadoso negro en Calypso, de Tatiana Lobo. en Silvia Nagy-Zekmi (Ed.). Moros en la costa. Orientalismo en Latinoamérica, Madrid: Iberoamericana, 2008

Coello, E. (2010). De paraísos, asaltos y laberintos. Notas a la novelística de Tatiana Lobo. Centroamericana, 19, 23-36.

Du Bois, W. E. B. (1992). This Double Consciousness. En C. Ricks (Ed.), The Faber Book of America (pp. 101). Londres: Faber. 
Germaná, C. (2010). Una epistemología otra: El proyecto de Aníbal Quijano. Nómadas, 32, 211-221. Recuperado de: http://www.redalyc.org/articulo. oa? $\mathrm{id}=105114733014$

Hernández R. (2011). Feminismos poscoloniales: Reflexiones desde el sur del Río Bravo. En L. Suárez y R. Hernández (Eds.), Descolonizando el Feminismo: Teorías y Prácticas desde los Márgenes (pp. 68-101). Madrid: Ediciones Cátedra.

Jiménez, A. (2002). El imposible país de los filósofos. San José: EUCR.

Lara, I. (2007). Beyond Caliban's Curses: The Decolonial Feminist Literacy of Sycorax. Journal of International Women's Studies, 9(1), 80-98.

Lobo, T. (1996). Calypso. San José: Ediciones Farben.

Mignolo, W. (2007). La colonialidad: la cara oculta de la modernidad. Cultural Studies, 21(1-2), 39-50.

Mohanty, C. (2011). Bajo los ojos de Occidente: Feminismo académico y discursos coloniales. En L. Suárez y R. Hernández (Eds.), Descolonizando el Feminismo: Teorías y Prácticas desde los Márgenes (pp. 112-161). Madrid: Ediciones Cátedra.

Molina, I. (2003). Costarricense por dicha: identidad nacional y cambio cultural en Costa Rica durante los siglos XIX y XX. San José: EUCR.

Ovares, F. et al. (1993). La casa paterna: escritura y nación en Costa Rica. San José: Editorial de la Universidad de Costa Rica.

Pratt, M. (2010). Ojos imperiales: Literatura de viajes y transculturación. México: Fondo de Cultura Económica.

Quesada, A. (1986). La formación de la narrativa nacional costarricense. San José: Editorial de la Universidad de Costa Rica. 


\section{La disputa del ser: voces y saberes en las mujeres....}

Quijano, A. (1992). Colonialidad y modernidad/racionalidad. Perú indígena, 13(29), 11-20.

Restrepo, E. y Rojas, A. (2010). Inflexión decolonial: Fuentes, conceptos y cuestionamientos. Popayán: Editorial de la Universidad del Cauca.

Singer, D. (2006). La construcción de la identidad nacional patriarcal en Misterio, de Manuel Argüello Mora. Letras, 39, 87-105. Recuperado de: http://www. revistas.una.ac.cr/index.php/letras/article/view/878

Wynter, S. (1990). Beyond Miranda's Meanings: Un/Silencing the 'Demonic Ground' of Caliban's 'Woman'. En A. Donnell y Lawson, S. (Eds.), The Routledge Reader in Caribbean Literature (pp. 416-424). London: Routledge.

\section{¿Cómo citar este artículo?}

Barboza Núñez E. (Julio-diciembre, 2018). La disputa del ser: voces y saberes en las mujeres, las pugnas coloniales, el Estado y el progreso en Calypso, de Tatiana Lobo. Revista humanidades, 8(2), 1-21. doi: http://dx.doi. org/10.15517/h.v\%vi\%i.31981 